\title{
El localismo global de un clásico. Una visita a las Tradiciones de Ricardo Palma desde la teoría aristotélica de la mimesis y de la Weltliteratur de Goethe ${ }^{1}$
}

\author{
Miguel Ángel Vega Cernuda \\ Universidad de Alicante \\ carsacer@gmail.com
}

\section{Resumen}

En el presente trabajo hemos glosado el valor universal de las Tradiciones de Palma a partir de la teoría de la mímesis aristotélica y como realización de lo que Goethe denominó Weltliteratur. Revisamos también la presencia de Palma en la edición, crítica y traducción internacionales.

Palabras clave: Tradiciones peruanas, teoría de la literatura, teoría de la recepción, traducción y literatura.

\section{Abstract}

In this paper we have glossed the universal value of Palma's Traditions from the theory of Aristotelian mimesis and as realization of Goethe's World literature. We have reviewed the presence of Palma in the international edition, criticism and translation.

Keywords: Peruvian Traditions, theory of literature, theory of reception, translation and literature.

l Parte del discurso pronunciado con ocasión de la admisión del autor como miembro correspondiente del Instituto Ricardo Palma de Lima. Se ha omitido fundamentalmente la segunda parte del mismo por limitación del formato. 
Miguel Ángel Vega Cernuda, Profesor Titular (U. Complutense). Catedrático (U. de Alicante), actualmente jubilado. Estudios de Filosofía y Teología (1960-1966). Estudios de Filología Moderna (Licenciado en Filología Moderna. 19691973) en U. Complutense. Becado en Tubinga (DAAD, 197375), Viena (ÖAD, 1980) y Berlín (DAAD, 1985). Doctor en Filología Alemana. Estancias de formación en Nimega, Perugia, Gante, Oxford, Lübeck (DAAD), Arles, Procida, Aarhus. Diversas distinciones internacionales. Profesor visitante en la U. de Münster (2002-2012). Director del Instituto Universitario de Traductores Complutense (1987-2003) Autor de un centenar de artículos y una docena de libros. (Temas: literaturas en lengua alemana, historia y teoría de la traducción, literatura misionera). Traductor literario (treintena de títulos del alemán, italiano, francés, danés: Casanova, Jacobsen, Goethe, Schnitzler, Haertling, etc.) 


\section{1. "Revisitar" como alternativa de "revisar": las Tradiciones como mímesis}

El título del presente congreso nos impone la ardua tarea de "re-visar" las Tradiciones Peruanas de Ricardo Palma, tarea para la que no me siento a la altura al no ser un estudioso de su obra cuanto un reincidente lector que puede afirmar, como hace Bryce Echenique, que de vez en cuando gusta de "volver a las Tradiciones". Sí me atrevo a otra tarea más modesta, la que viene expresada en un parónimo del término propuesto: no pretendo "re-visar", sino "re-visitar", término este que entiendo en el sentido que recoge el correspondiente término inglés revisit en el Oxford Dictionary y que en castellano ya viene registrado a su vez en el diccionario de Pedro Labernia de 1891 Diccionario de la lengua castellana con la correspondencia catalana y latina. ${ }^{2}$ En él se definía el término como "visitar nuevamente" y se derivaba del verbo "ver". Pues bien, tanto en el sentido semántico del término inglés revisit ("considerar un objeto desde otra perspectiva") como en el español "revisitar" ("visitar de nuevo"), voy a intentar hacer algunas consideraciones sobre las Tradiciones con la modesta intención de hacer una visita de cortesía y reivindicatoria de su autor. A modo de introducción, propongo un resumen del núcleo conceptual que estructura mi trabajo y bajo el cual hago esta visita a la obra de Palma. En él parto de un concepto fundamental y fundacional de la poética y de la teoría literaria: el concepto de mímesis, imitación o representación. Como es sabido, la retórica aristotélica ha señalado tres posibles funciones a la poesía: la mimesis o

2 Este diccionario incluía ocho mil términos no presentes en el de la RAE de entonces En esto, el lexicólogo catalán iba parejo con los propósitos de D. Ricardo, quien, como es bien sabido presentó a la Academia sus propuestas personales de incorporación de voces al Diccionario. 
imitación, la poiesis o creación y la catarsis o liberación. ${ }^{3}$ Y resulta evidente que la escritura palmista, especialmente las Tradiciones, se inscribe en la funcionalidad literaria de la mímesis.

Ahora bien, la mímesis literaria puede adoptar dos realizaciones: la de la concreción localista y la de la abstracción situacional. La primera supone un lector implícito inmediato; la segunda puede llegar a lectores más universales. Pues bien, las Tradiciones en general y las de Ricardo Palma en particular se inscriben en esta funcionalidad de la mímesis localista. Como prueba vaya el siguiente texto escogido al azar ("Un predicador de lujo", Tradiciones peruanas, 1870):

Huacho era, en el siglo anterior, un villorrio de pescadores y labriegos, gente de letras gordas o de poca sindéresis, pero vivísima para vender gato por liebre. Ellos, por arte de birlibirloque o con ayuda de los polvos de pirlimpimpim, que no sabemos se vendan en la botica, transformaban un róbalo en corvina y aprovechaban la cáscara de la naranja para hacer naranjas hechizas.

Los huachanos de ahora no sirven, en punto a habilidad e industria, ni para descalzar a sus abuelos. Decididamente las razas degeneran.

A los huachanos de hoy no les atañe ni les llega a la pestaña mi cuento. Hablo de gente del otro siglo y que ya está criando malvas con el cogote. Y hago esta salvedad para que no brinque alguno y me arme proceso, que de esas cosas se han visto, y ya estoy escamado de humanas susceptibilidades y tonterías. (Palma, 2014:133).

3 Entendemos por "retórica aristotélica" la sistematización poética realizada por los preceptistas clásicos basándose sobre todo en la Poética del filósofo griego. Al respecto remitimos a la versión de García Yebra, Gredos, Madrid, 1974. 
Este texto producirá en un "lector implícito" (el inconscientemente pretendido por el autor) una identificación por simpatía o familiaridad, mientras causará "extrañamiento" (Verfremdung denominó B. Brecht a esta reacción cuando de público teatral se trataba) en el "lector empírico" (el lector real que se sitúa más allá del implícito) ajeno al ambiente. Evidentemente, a lectores no inmediatos de las Tradiciones y ajenos a la cultura de la pesca/pescado les resultará difícil congeniar lingüísticamente con expresiones tales como "vender róbalo por corvina”. Y lo mismo sucederá con el que no tenga una cierta familiaridad con la manipulación de la naranja, que difícilmente interpretará la transformación "de la cáscara de la naranja en naranja hechiza". Finalmente, Huacho, localización de la "fábula", puede resultar, a pesar de la proximidad peruana de este municipio a la capital, tan críptica como lo sería la legendaria Thule del poema de Goethe (El rey de Thule) para el lector romántico.

Avanzando un poco más en mi explicación, propongo un ejemplo máximo del posible extrañamiento causado en el lector por el texto: un pasaje emblemático de la literatura peruana: Yawar Fiesta de J. M. Arguedas (1974: 2):

En la puna y en los cerros que rodean al pueblo tocaban ya los wakawak'ras. Cuando se oía el turukpullay en los caminos que van a los distritos y en las chacras de trigo, indios y mistis hablaban de la corrida de ese año.

-iCarago! Pichk'achuri va para juirme. Siempre, año tras año, Pichk'achuri ganando enjualma, dejando viuda en plaza grande - hablaban los comuneros.

-K'ayau va a traer Misitu de K'oñani pampa. Se han juramentado, dice, varayok alcaldes para Misitu. 
-iCojodices! Con diablo es Misitu. Cuándo carago trayendo Misitu. Un ’hay káry para Misitu de K’oñani.

Por razones de espacio, tenemos que omitir la exégesis tanto de los "reales" como de sus soportes lingüísticos de este texto, ambos profundamente marcados por el localismo e inasequibles para el ajeno a la cultura andina.

\section{Vargas Llosa sobre Ricardo Palma}

Quizás por la concreción localista que posee el relato de Palma, el gran analista de la peruanidad que es Mario Vargas Llosa, en el prefacio que abre el I volumen de la reciente edición de las Tradiciones (2007: 27) califica a Palma de "valor nacional" peruano: "no solo por los méritos literarios de su obra y por la repercusión alcanzada, es Palma un valor nacional. Lo es también por su condición de escritor eminentemente peruano", escribía el novel escritor en 1956. Y en este mismo sentido, Bryce Echenique (1992: XVII) afirmaba que Palma representaba para la literatura peruana "un papel muy semejante al que representó Mark Twain para la literatura norteamericana."

Lejos de mí está pretender enmendar la plana al maestro de la narrativa moderna y, not last but not least, gran crítico de la cultura, tal y como demuestran obras tales como la Utopía de lo arcaico o La civilización del espectáculo. Por supuesto que Ricardo Palma es un valor nacional, pero don Mario permitirá, sin duda, una breve apostilla desde la perspectiva actual. Palma, además de un signo de identidad nacional, es un valor poético de rango internacional o, lo que es lo mismo, una figura de la literatura universal. Y esto, insistimos, a pesar del profundo localismo temático de sus obras, localismo que impregna, por activa y por pasiva, todo el ductus de las Tradiciones. Todo su corpus literario, desde sus Anales de la inquisición, que al final incluyó en sus Tradiciones, hasta su nutrido corpus epistolar, no 
se puede entender si no se pone como hipocentro de su astro a la realidad social e histórica de Lima y del Perú.

Todo el paisaje y el paisanaje, tanto del coloniaje como del criollaje republicano, están presentes en su obra: el corregidor y el oidor; el alcalde y el virrey; el campanero bellaco y el maestrescuela de escasas letras; la retirada dama de beaterio y la no tan retirada; la linda tapada y la sin tapar y no tan linda; jesuitas, dominicos y agustinos, a los que, por cierto, nunca perdió ocasión de poner como chupa de dómine; el virrey Amat; el así llamado "libertador" Bolívar, que no lo fue tanto; o el general Salaverry; la Alameda, Acho y la Recoleta; Lampa, Ayacucho o Cuzco. En resumen, toda la historia peruana y la diversa sociedad de este territorio en cuatrocientos años están presentes en ese políptico que son las Tradiciones, y que, semejantes en su composición a las apocalípticas tablas del Bosco (quizás cabría retitular la obra de Palma con el título de una tabla del flamenco: "mesa de los pecados capitales"), mediatizan el más vívido cuadro de costumbres de la abigarrada sociedad peruana. Por eso, cuando Mariátegui hablaba de Palma, lo hacía en el contexto de sus 7 ensayos de interpretación de la realidad peruana (1928). ${ }^{4}$

Y en este sentido espero que se me admita una propuesta sintetizadora: la obra de Palma es el más completo tratado literario de etnografía peruana. ${ }^{5}$ En su pluma palpita y vive todo el pueblo peruano. Vargas Llosa tenía razón en el mencionado discurso, al hacer una afirmación que constataba la percepción fundante de la crítica romántica, sobre todo la alemana: "La literatura y el arte son siempre manifestación deliberada o inconsciente de una colectividad" (Ibídem). Es decir, todo arte

4 Apartado IV del capítulo "El proceso de la literatura".

5 Todo ese mundo palmista quizás coincida con el concepto de "perricholismo", si bien es este un concepto que solo en cierta ideología puede tener, muy convencionalmente, un sentido peyorativo. Desde el punto de vista de la etnografía literaria tiene un valor innegable. 
siempre o casi siempre es Volksdichtung, creación de un pueblo. En ese sentido, podemos considerar a Ricardo Palma como instrumento y expresión de la peruanidad que en su tiempo se estaba constituyendo.

Pero, ¿cómo casa ese localismo o nacionalismo de la escritura palmista con el carácter internacional de la misma que proponemos? En efecto, el colorido local que impregna el relato palmista parecería ir contra la universalidad de sus códigos y consiguientemente de la difusión general de su obra. Pero el tema tiene más ángulos de los que aparecen y exige mayor consideración.

\section{La literatura entre concreción local y abstracción ideal. O de lo global y lo local en la literatura}

Dos son las posibilidades de las que dispone el poeta a la hora de configurar lo que la teoría literaria denomina plot en inglés, fabel en alemán, intrigue en francés o "argumento" en español: 1) el de la concreción espacio-temporal; y 2) el de la abstracción de los coloridos locales y epocales del texto.

Los autores de Fausto, de La divina comedia, de Hamlet o de La Metamorfosis han trabajado mayormente con este segundo método, prescindiendo de coloridos sociales concretos y convirtiendo sus objetos poéticos en mero soporte de una realidad intemporal. El "cuarto de estudio gótico" en el que Fausto cierra el pacto con Mefisto es un "topos" teórico que carece de ese colorido localista de los espacios en los que "Don Dimas de la Tijereta" disputa con Lilit la posesión de su "almilla". Mientras, el "espacio gótico" de Fausto el lector podrá situarlo tanto en la torre de la catedral de Estrasburgo como en la plaza de la ciudad nueva de Praga ${ }^{6}$, lo que significa que es un objeto

6 Como se sabe, una tradición praguense fija la morada del alquimista en esa plaza. 
poético “acrónico" y "atópico". Por su parte, los tres soldados de Hamlet imanifiestan alguna referencia local si consideramos que llevan nombres tan poco daneses como Marcelo, Francisco o Bernardo? ¿Se imaginan un cortesano en el séquito del rey danés del XVI con el nombre de Laertes? Christian, Olav o Harald serían más propios. Por eso, Ralph Waldo Emerson, en un breve ensayo sobre la poesía (2014: 297 y s.), afirmaba, con relación a los contenidos del poema, que "el objeto [poético], cuando se usa como tipo, revela un segundo valor [...] Las cosas admiten ser usadas como símbolo".

En efecto, la situación del argumento de Hamlet en la corte danesa de Elsinore solo es una referencia a la preceptiva clásica, la unidad de lugar, no una referencia etnográfica o histórica a tomar en serio. El relato de Saxo Grammaticus, fuente del argumento shakesperiano, situaba el episodio del drama en el lejano siglo VIII y sobre un promontorio de la península de Jutlandia. Nada que tuviera que ver con la acción del drama inglés. Y el público que en el Globe Theatre de Londres asistía a la representación del Hamlet difícilmente podía tomar la tragedia del príncipe como fuente de información sobre la sociedad danesa de la época. Y erraría quien pretendiera servirse de La vida es sueño de Calderón como fuente de información sobre el reino de Polonia. Por su parte, Kafka prescindía de cualquier referencia local en La Metamorfosis. El dormitorio en el que Gregor Samsa ha despertado convertido en una repugnante cucaracha no se sitúa necesariamente en la ciudad vieja praguense. No solo la peripecia que inicia La Metamorfosis de Kafka (1915), sino todo el relato, un lector peruano podría situarlo, sin pérdida de quantum comunicativo, en un barrio cuzqueño:

Cuando Gregorio Samsa se despertó una mañana después de un sueño intranquilo, se encontró sobre su cama convertido en un monstruoso insecto. Estaba tumbado sobre su espalda dura, y en forma de caparazón y, al levantar un poco la 
cabeza, veía un vientre abombado, parduzco, dividido por partes duras en forma de arco, sobre cuya protuberancia apenas podía mantenerse el cobertor, a punto ya de resbalar al suelo. Sus muchas patas, ridículamente pequeñas en comparación con el resto de su tamaño, le vibraban desamparadas ante los ojos. ${ }^{7}$

Es obvio que semejante opción expresiva, la de la abstracción de lo local, facilita el acceso de la obra a ámbitos de comunicación universales al concentrar el núcleo del argumento, sus anécdotas y peripecias, en categorías universales de lo humano (en el caso de Hamlet, la duda o la venganza; en el de Samsa, la alienación laboral).

La segunda opción de comunicación poética es la de la concreción local, que tiene como "lector implícito" a aquel que se mueve en el entorno inmediato del autor. Tanto el argumento como la forma de la obra adoptan modos y modalidades más asequibles a un público del que se pretende una reacción de "deleite", más que de "provecho". Tal es la opción del costumbrismo que, en parte importado de Europa como una derivación del romanticismo, hace furor en las repúblicas americanas como praxis fundamental de lo que Palma llamó la "filoxera literaria". En España, la novelista hispano-alemana Fernán-Caballero (La Gaviota) y el cronista Mesonero Romanos (Escenas matritenses) o, en Francia, Paul-Louis Courier (Gazette du village), se habían hecho patrocinadores del nuevo género surgido a principios de siglo XVIII, favorecido por la irrupción del periodismo y que Adison había denominado sketch of manners. Del célebre binomio horaciano (Aut prodesse volunt, aut delectare poetae, es decir, "o aprovechar o deleitar es lo que pretenden los poetas"), los promotores de esa "filoxera literaria" primaron

7 Kafka, Franz, Die Verwandlung. Consultado en: http://gutenberg.spiegel.de/ buch/die-verwandlung-9760/1 Traducción propia. 
el segundo elemento: el delectare, que, basado mayormente en el auto-reconocimiento, se entronizó en la praxis literaria del segundo romanticismo. Y tal hicieron, como digo en un primer momento, los tradicionistas americanos, que buscaron el virtuosismo descriptivo, la visión caracterizadora, la forma corta expresivamente condensada en la que la encriptación local dificultaba el acceso al lector no iniciado.

Tales son los rasgos que caracterizan las Tradiciones y, en otro orden de cosas, el arte, por ejemplo, de Pancho Fierro, que solo un limeño arraigado (o "converso", que los hay) podrá descifrar e identificar. Hasta un cuento tan "metafísico" como "Don Dimas de la Tijereta”, en el que se tematiza la lucha entre las fuerzas del mal, tiene su localización precisa en un rincón de la topografía limeña: en el Portal de los Escribanos, perfectamente identificable hoy en día en la Plaza de Armas capitalina. Por si fueran insuficientes las referencias locales, Palma remarca los contenidos con giros, modismos o, incluso, deturpaciones) fonéticas o sintácticas que caracterizan el relato como orientado a un público inmediato.

¿Se imaginan a un lector alemán apreciando y gustando el virtuosismo léxico de don Ricardo, traductor mediante por supuesto, en expresiones, colocaciones y fraseologismos tan locales como "real moza", "criar malvas con el cogote", "pindonga", "no que nones", "no hacerse de pencas"? ¿Se imaginan a un traductor que pueda dar buena cuenta de la habilidad estilística que suponen sus quiasmos, arcaísmos, antítesis y paradojas, hipérboles y perífrasis tales como "capaz de dar un espanto al mismo miedo", "dar la carne al diablo y los huesos a Dios"? ¿Sabrá recoger el traductor francés la connotación e intencionalidad que porta la expresión "domingo de Quasimodo"? Si a ello se suma la ironía, columna vertebral del estilo palmista, el lector no iniciado, ¿sabrá conectar el doble plano de la ironía, a saber, la referencia del "decir" con 
la del "querer decir"? Efectivamente, el género costumbrista es por definición argumental y formalmente críptico y habla básicamente a lo que más que "lector implícito" podríamos calificar de "lector implicado". Por eso, aludiendo a ese carácter críptico, un editor alemán de las Tradiciones se preguntaba: "¿Qué son las tradiciones?". Se contestaba: "algo que no se puede traducir." (Stelzman, 1928: 3).

\section{Una tercera vía de formalización literaria: lo global localizado}

Pero el asunto encierra su paradoja, pues la expresión de lo local, la expresión de una colectividad determinada puede constituir fundamento de validez universal. Si la abstracción de lo local es un factor importante a la hora de obtener el valor de lo universal literario, también la concreción de lo local como criterio de formalización del discurso literario puede trascender el aquí y el ahora, aunque para lograrlo el autor deberá manifestar una pericia especial para que el producto final de su actividad redactora resulte operante, más allá del "lector implícito", ante un "lector empírico" que transciende al primero.

Y este debería ser el primer malentendido a deshacer: lo local y lo global poético no se excluyen sino que están llamados a integrarse. Es evidente que muchas de las obras marcadas por lo local no han entrado en el panteón universal de la literatura. Han sido innumerables los autores que han ensayado el localismo como clave de su formalización poética y que han fracasado a la hora de lograr una dimensión universal quedándose para el consumo interno del grupo originalmente destinatario. El colorido regional de los poemas del extremeño Gabriel y Galán (1870-1905), que en sus Extremeñas cantó la vida campestre de esa bella región española no ha roto la barrera de lo local y ha hecho de su autor un objeto de consumo poético de pocos. 
Tampoco el escritor colombiano Tomás Carrasquilla (18581940), representante de lo que se ha llamado "antioqueñismo literario", con una pluma muy próxima a la del tradicionista peruano, no ha logrado superar los límites del consumo lector nacional. Siendo merecedor, por supuesto, de un mayor conocimiento, Aquileo Echeverría (1866-1909), a quien Rubén Darío alabó sobremanera en su momento, no ha logrado traspasar las fronteras patrias y ninguna editorial extranjera se ha atrevido a publicar sus obras. Los localismos de estos autores, no en último términos lingüísticos difícilmente reproducibles, los condenaron al ostracismo. Arduo resultará para cualquier lector "no implicado" mantener en semejantes textos un interés continuo más allá de la curiosidad.

Sin embargo, ha habido autores que, habiendo adoptado esa encriptación localista, han logrado una dimensión universal. Carlos Luis Fallas, compatriota de Echeverría, narrando el mundo de la explotación en las plantaciones bananeras de Centroamérica por obra y gracia de la United Fruit Company (de donde deriva el título), ha conseguido una cierta proyección global al colocar su obra Mamita Yunai en varias lenguas universales. Y un autor tan localista como Vargas Llosa, cuya obra -desde Conversación en la catedral (solo habría que recordar la paradigmática interrogación localista que se hace Zavalita en esa horrible avenida Tacna: “iEn qué momento se jodió el Perú, Zavalita?") hasta El sueño del celta, pasando por Lituma en los Andes o Pantaleón y las visitadoras- puede considerarse una reflexión sobre la peruanidad, ha conseguido la universalidad al pasar a la veintena de lenguas en las que está presente.

Pues bien, ¿qué valor añadido necesita una obra localista para constituirse en un valor universal? ¿Cuál es el criterio, el factor que hace que ciertos localismos literarios pasen a lo global, a lo universal, mientras otros quedan en los límites reducidos del grupo que inicialmente lo recibió? 
No es preciso destacar que quien pretenda penetrar en el patrimonio universal literario (y tal es la acepción primaria del concepto gotheano Weltliteratur) debe ser previamente un clásico nacional. Pero además debe ser autor de una obra en la que lo local solo sea un velo de la metafísica antropológica, si por metafísica se entiende lo que dice el término aristotélico:

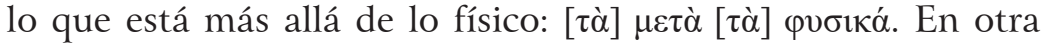
ocasión, glosé aquí la base localista del universalismo de Cervantes, cuyo Quijote se convirtió en obra de la literatura mundial gracias a la poetización de un mundo de referencias y reales concretos castellanos: desde los molinos manchegos hasta la dieta castellana que mantenía el ingenioso hidalgo, pasando por la meseteña y rústica cueva de Montesinos o el prosaico bachiller Sansón Carrasco. Todos ellos eran "reales" muy locales en los que el autor pretendía escenificar la agonía o lucha entre concreción y trascendencia, entre necesidad y libertad.

Dicho de manera general cabe afirmar que también el código local de una escritura puede ser alusivo a las constantes metafísicas de lo humano. Lo local puede ser mero trasunto de aquella "comedia humana" que Honoré de Balzac, por ejemplo, supo encarnar en el París de la Restauración francesa. Es, entonces, cuando los comportamientos generales humanos se encarnan en un localismo colorista, que, sin embargo, deja transparentar los valores y las valencias de lo general humano. De este modo, esa escritura mimética tendrá vocación de universalidad. Y eso es lo que precisamente sucede con la escritura de Palma. Como Cervantes en su Quijote, Palma en sus Tradiciones hizo de lo peruano un trasunto de lo general humano. Lo local y costumbrista en ese caso no eran un fin, sino un medio. No en vano Raimundo Lazo (Porrúa, Méjico: 1980, pág. XXXIII), en la edición mejicana de las Tradiciones, habla de "comedia humana", refiriéndose a la estilización imaginativa que de la historia hace Palma. 


\section{El proceso de recepción en la Literatura Mundial (Weltliteratur) o el traductor alquimista destilador de lo local en lo universal}

Pero la valencia global de lo local es mera condición, no causa eficiente y suficiente de universalidad literaria. Para que una obra se convierta en patrimonio de la humanidad deben conjurarse una serie de factores extrínsecos que la hagan pasar al mercado global. Goethe, él mismo un eficaz rastreador de nacionalidades literarias (como demuestra su colección de cantos populares Stimmen der Völker in Liedern, "Voces de los pueblos en sus canciones"), describía el término por él creado Weltliteratur en sus Escritos sobre arte y Literatura y en sus Conversaciones con Eckermann (1836), especialmente en una de ellas, la del 21 de enero de 1827. En ella, preveía el surgimiento inmediato de una dimensión global de la literatura.

Veo cada vez más [...] que la poesía es un bien común de la humanidad, y que surge en todos los lugares y épocas, en cientos y miles de seres humanos. [...] Por eso me gusta hurgar en naciones ajenas y recomiendo a cualquiera hacer lo mismo. Literatura nacional ya no dice gran cosa, llegó la época de la literatura mundial, y ahora cada uno tiene que ayudar a acelerar esta época. ${ }^{8}$

Pues bien, tres son los vectores fundamentales que llevan a una obra al territorio de la literatura mundial: 1) el editor, 2) el crítico y, 3) sobre todo, el traductor. Y los tres han actuado y están actuando, aunque en distinto grado, en la gestión del legado palmista:

8 Citado según http://gutenberg.spiegel.de/buch/gesprache-mit-goethe-in-denletzten-jahren-seines-lebens-1912. Traducción propia. 
A. El hecho de que el castellano sea un idioma multinacional ha posibilitado que las Tradiciones Peruanas hayan saltado editorialmente los límites del espacio peruano en el que se sitúa el primario "lector implícito" o lector intencional de Palma, lo cual constituye ya una primera prueba de que el localismo palmista lleva in nuce la vocación de universalidad. Recordemos que en España, todavía en vida del autor, se publicaría una serie de ediciones para el público panhispano: en la editorial Maucci de Barcelona Apéndice a mis últimas tradiciones (1910) y Las mejores tradiciones peruanas (1918); y en Madrid (Calpe: 1919) vio la luz una edición que algunos estudiosos han tomado como la edición reglada.

Anteriormente, la edición que Montaner y Simón había publicado en Barcelona (Tradiciones peruanas, 1893-96), en lujosa edición, había sido propuesta por el autor como una especie de edición princeps. La edición de Aguilar sirve en ocasiones de referencia bibliográfica y el CSIC (1992) conmemoró la efeméride del año con la edición de unas sesenta "tradiciones". La de Cátedra (1994), con una selección de casi ochenta títulos), se presenta acompañada de un exhaustivo e interesante estudio. Y la BVC, de la Universidad de Alicante, pone al alcance del cibernauta, para consulta o lectura, una selección representativa de las Tradiciones. Y otras ediciones no peruanas son las mejicanas de Porrúa (1980); la argentina de Difusión (1977) o la chilena de Ercilla (1945) con prólogo de Luis Alberto Sánchez.

B. Por lo que respecta a la crítica, amplio eco ha tenido la obra palmista, tanto dentro como fuera de las fronteras nacionales. La crítica nacional (Mariátegui, Núñez, Porras Barrenechea, Bazán, Pantigoso, etc.) ha hilvanado ya un denso corpus de títulos que analizan y explicitan los implícitos culturales o las encriptaciones lingüísticas o históricas de las Tradiciones. Las trifulcas del autor con González Prada ("ni historia 
ni cuento" diría este polemista de las Tradiciones) o los comentarios de Riva-Agüero ("la obra de Palma sería la mejor vía de acceso al conocimiento de la Colonia”) figuran en muchas exposiciones críticas y son un ejemplo de esa omnipresencia de Palma en la crítica literaria del país.

Fuera de los límites nacionales, J. M. Oviedo en la Historia de la Literatura Hispanoamericana (coord. Luís. Í. del Moral, 1999: 258 y ss.) alinea a Palma en el marco de un segundo romanticismo que va tras las huellas de Scott, Chateaubriand, Larra, Gil y Carrasco o Mesonero Romanos. Agustín del Saz, en Literatura Iberoamericana (1978: 35) hace de Palma el colofón del romanticismo histórico. Y la página que la BVC dedica a Palma lo menciona como "una de las altas cumbres del vasto y variado universo de autores decimonónicos". El Manual de literatura hispanoamericana (2002) de la U. de Pamplona señala a Palma como "el autor que eclipsó al resto de narradores peruanos”. Karl Kohut (2016: 200) afirma que con las Tradiciones el costumbrismo americano alcanzó su punto culminante.

La historia de la literatura hispanoamericana de Michael Rossner (2007: 172) califica las Tradiciones de un verso suelto en el marco general de dependencia de modelos europeos por parte de las literaturas americanas. Roy Tanner, de la Truman State University, le califica de "neólogo por excelencia."9 En definitiva, ni loas ni aprecios y ni siquiera tachas, explícitas o implícitas (no en último término las de Salazar Bondy: Lima la horrible), le han faltado a Palma en los estudios que se le han dedicado en historias o revistas de ciencia y crítica literarias (Revista de Estudios Hispánicos, Revue Hispanique, Hispanic Review, etc.).

9 Biblioteca Virtual Miguel de Cervantes, 2007. 
C. Pero la globalización o universalidad obtenida a través de la crítica sería meramente teórica, amén de "regional" y parcial. Un artículo en la Revue hispanique no convierte en universal a un autor; simplemente lo hace objeto de estudio literario. El vector fundamental de la Weltliteratur, vector a su vez de lo que Goethe llamaría das erweitertes Vaterland (la patria ampliada) es el traductor, que hace que la obra supere el espacio lingüístico y cultural en el que nace, a costa de destilar lo que de lo local del texto original cabe en la universalidad de la lengua terminal. Para Goethe, la traducción era el rito que daba carta de ciudadanía universal a la obra literaria y afirmaba que una literatura nacional introvertida se aburre: "Una literatura se aburre en definitiva si no es reavivada con participaciones extranjeras." (Jubiläums-Ausgabe: 136137). ${ }^{10} \mathrm{Y}$ en cartas a Carlyle, Goethe encomiaba en este sentido la importancia de la traducción:

Los esfuerzos de los mejores poetas de todas las naciones se orientan desde hace tiempo a lo general humano (...). El traductor debe considerarse como el intermediario del comercio espiritual que ha hecho tarea propia el fomento de ese intercambio mundial. Por más que se hable de la insuficiencia de la traducción es indiscutible que es una de las tareas más importantes y dignas del ser humano (20/7/27). [...] La conexión entre el original y la traducción expresa más claramente la relación de una nación a otra $[1 / 1 / 28] .{ }^{11}$

10 Citado según Schriften zur Literatur. Jubiläums-Ausgabe. Stuttgart: J. G. Cotta, 1912.Tr. propia.

11 Las cartas de Goethe a Carlyle, junto con las “conversaciones” de Eckermann, constituyen el corpus fundamental de su teoría de la "Weltliteratur". Dada la falta de espacio para exponerla, remitimos a su lectura: www.zeno.org/ Literatur/M/Goethe, +Johann+Wolfgang/Briefe. 
Es una realidad crítica inapelable que la literatura universal se constituye gracias a las aportaciones de las literaturas nacionales que la traducción vehicula. Por eso, mientras un autor no traspase las propias fronteras lingüísticas, es decir, mientras no sea traducido, no podrá figurar en el panteón de la literatura universal. En el acto primario de la escritura, la universalidad poética no está ordinariamente en el horizonte inmediato del autor. Su destinatario es el "lector implícito", el lector de la propia lengua/cultura. Pero a la obra así concebida para un lector implícito le pueden sobrevenir a través de la traducción toda una serie de diversificados lectores que quedan englobados en lo que se denomina el "lector empírico". Kafka pretendió escribir para su momento y entorno ger-mano-parlante y no tuvo idea que el lector del futuro le convertiría en el autor más universal del siglo XX. No en vano su "maniera", como las del Dante o Cervantes (lo dantesco, lo quijotesco), expresa un modo de concebir el mundo.

En este contexto, la traducción debe ser el factor decisivo en la internacionalización de Ricardo Palma que, poco a poco, por desgracia muy lentamente, va visitando otras lenguas. Permítase pues un repaso a esa presencia global del localismo palmista gracias a la traducción

\section{Lo por hacer o a la mitad de camino}

Si se consideran estos datos de la internacionalidad de la obra de Palma, puede comprobarse que, a pesar de su potencial condición de autor universal, la situación de su recepción no es satisfactoria. De ellos cabe deducir el largo camino que queda por andar. Cuatro son los déficits fundamentales perceptibles en la recepción internacional de Palma: 
A. Ausencia de versiones en ámbitos lingüísticos de gran relevancia para la llamada Weltliteratur. Son numerosísimos los ámbitos lingüísticos en los que Ricardo Palma todavía no constituye una entrada de sus repertorios bibliográficos. Los cientos de millones de potenciales lectores rusos, los siete millones de lectores checos, los diez millones de suecos, los doce millones de holandeses son, por ejemplo, espacios culturales que no gozan todavía de la enjundiosa narrativa de Palma.

B. Carácter selectivo de las ediciones: obviamente resulta tarea ardua cuando imposible hacer una versión integral de las Tradiciones, dada la dificultad estilística que estas comportan. De ahí derivan las ediciones traducidas "restringidas" (entre quince y sesenta títulos, que quedan pequeños frente a los cuatrocientos largos que integran el catálogo total de la obra palmista). Los criterios de selección parecen derivar la edición hacia títulos en los que la actividad versora es más llevadera, opción por lo demás legítima, pero que hará perder entidad a la edición traducida.

C. Divergencia en los objetivos editoriales: mientras unas ediciones motivan la presentación de la obra (OUP), otras (Liguori, Groos) priman la función didáctica frente al disfrute literario al poner el relato palmista al servicio del aprendizaje lingüístico o cultural.

D. Grandes y numerosas deficiencias, en cuanto a la exactitud y adecuación, no solo léxica sino también estilística de los dos textos, el terminal y el original. 
— El LOCALISMo global DE UN CLÁSICO. UNA VISITA a LAS TRADICIONES DE RICARDO PALMA —DESDE LA TEORÍA ARISTOTÉLICA DE LA MIMESIS Y DE LA WELTLITERATUR DE GOETHE

\section{A modo de conclusión}

Estas versiones son pruebas de la dimensión global que paulatina y merecidamente van adquiriendo nuestro personaje y su obra, dimensión que debería fomentarse. Y es este un aspecto que incumbe a la tarea de difusión cultural de un país. Un cierto mercantilismo se impone al respecto: la importación de bienes literarios extranjeros (y el Perú y, en general, las naciones hermanas hispanas en este aspecto no deberían ser meras subsidiarias del editorialismo español) debe ir acompañado por la exportación de los productos nacionales, ya que estos son piedra angular de la imagen cultural de un país en el exterior.

El interés y la curiosidad que hoy en día suscita la historia peruana, tanto de hogaño como de antaño, sería un motivo para que el estado o, en su defecto, la sociedad civil nacional, a través de sus instituciones o de sus grupos de presión o de opinión, se mostrasen interesados en la difusión de la propia cultura. La caracterizada gastronomía peruana no basta para dar imagen al país. No solo de pan vive el hombre. Por otra parte, el poliglotismo presente en la actual sociedad peruana, producto en parte de un mestizaje cultural derivado del mestizaje biológico, junto con la existencia de unos cuadros de traductores que salen de las maestrías nacionales de traducción, deberían inducir a emprender unas actuaciones en equipo que llevasen a dar una imagen exterior más completa a uno de los nombres más característicos de nuestra cultura.

El inquilino de la casona de Miraflores, sin ser el padre de las letras peruanas (tal título le correspondería al mestizo hispanoinca que en la catedral cordobesa espera la resurrección de los muertos), sí es, junto a los clásicos modernos de la nación (Vallejo, Arguedas o Vargas Llosa), un "clásico universal". Y si la lengua castellana puede ser calificada como la lengua de Cervantes o la italiana como la lengua del Dante, a Ricardo 
Palma se le puede considerar epónimo de la variante peruana del español literario. Pero su valor universal está todavía a medio hacer. Mientras no se active, a través de la traducción, su potencial de comunicación global, Palma quedará en un valor universal en potencia. Quizás esta sea la tarea del futuro en una institución que lleva el nombre de Ricardo Palma: hacerle más universal.

\section{Bibliografía}

Arguedas, J. M. (1974), Yawar fiesta. Buenos Aires: Losada.

Bryce Echenique, A. (1992), prólogo a Ricardo Palma, Tradiciones Peruanas. Madrid: CSIC.

Eckermann, P. (1896), Gespräche mit Goethe. Stuttgart: Cotha.

Emerson, R. W. (2014), Ensayos. Madrid: Cátedra.

Goethe, J.W. (1912), Schriften zur Literatur. Stuttgart: JubiläumsAusgabe.

Kafka, Fr., Die Verwandlung. Consultado en: http://gutenberg.spiegel. de/buch/die-verwandlung-9760/1. Consultado el 17/03/18.

Kohout, K. (2016), Kurze Einführung in Theorie und Geschichte der Lateinamerikanischen Literatur. Berlín: Lit Verlag.

Lazo, R. (1980), “Introducción” a Tradiciones peruanas. Méjico: Porrúa.

Oviedo, J. M, "Ricardo Palma", en Madrigal Luis (coord., 1999) Historia de la literatura hispanoamericana. II: "Del neoclasicismo al modernismo". Madrid: Cátedra.

Mariátegui (1928), 7 ensayos de interpretación de la realidad peruana. Lima: Amauta. 


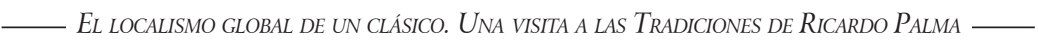
DESDE LA TEORÍA ARISTOTÉLICA DE LA MIMESIS Y DE LA WELTLITERATUR DE GOETHE

Palma, R. (1992), Annais da Inquisiçao de Lima. Sao Paolo: Edusp. 142 págs.

-- (2004) Peruvian Traditions. USA: Oxford U. Press. 263 págs. (2001) Tradizioni Peruviane. Raconti della terra degli incas. Napoli: Liguori. 169 págs.

--------- (1938) Traditions peruviennes. París: Institut International de Coopération Intellectuelle. 260 págs.

Traditions peruviennes. Bordeaux: Presses Universitaires de Bordeaux. 256 págs.

(2014) “Un predicador de lujo". En Tradiciones peruana Primera/Segunda series.Lima: Universidad Ricardo Palma.

Pedraza, F. B. (coord., 2002), Manual de literatura hispano-americana, Cenlit II. Pamplona.

Roesner, M. (2007), Lateinamerikanische Literaturgeschichte. Stuttgart: Metzler Verlag.

Saz, A. (1978), Literatura Iberoamericana. Barcelona: Juventud.

Stelzmann, A. (1928), Auswahl aus den Tradiciones peruanas. Heidelberg: J. Groos.

Vargas Llosa, M. (2007) Palma valor nacional. En Ricardo Palma, Tradiciones peruanas. Lima: Universidad Ricardo Palma.

Recibido el 13 de diciembre de 2017 Aceptado el 29 de enero del 2018 